\title{
Formation of Particle Structure in Plasma Treatment of Granulated Powder Based on Titanium
}

\author{
Anton E. Chesnokov* and Andrey V. Smirnov \\ Khristianovich Institute of Theoretical \\ and Applied Mechanics SB RAS \\ 4/1 Institutskaya Str., Novosibirsk, 630090, Russia
}

Received 25.04.2018, received in revised form 20.05.2018, accepted 01.02.2019

The paper presents the results of a study of the physico-chemical characteristics of powders obtained in thermal plasma during the treatment of a granular powder of two compositions: 1 granules consisting of ultrafine titanium particles; 2 - granules of the composition of ultrafine titanium particles and $20 \mathrm{wt}$. \% ultrafine of titanium nitride. The phase and granulometric composition is determined, the internal structure of the processed powder particles is studied.

Keywords: spherical powders, plasma torch, plasma jet, titanium, titanium nitride, granulation.

Citation: Chesnokov A.E., Smirnov A.V. Formation of particle structure in plasma treatment of granulated powder based on titanium, J. Sib. Fed. Univ. Eng. technol., 2019, 12(2), 203-213. DOI: 10.17516/1999-494X-0129.

\section{Формирование структуры частиц}

\section{при плазменной обработке гранулированного порошка}

\section{на основе титана}

\author{
А.Е. Чесноков, А.В. Смирнов \\ Институт теоретической и прикладной механики \\ им. С.А. Христиановича СО РАН \\ Россия, 630090, Новосибирск, ул. Институтская, 4/1
}

B работе представлены обобщенные результаты исследования физико-химических характеристик порошков, полученных в термической плазме при обработке гранулированного порошка двух составов: 1 - грануль, состоящие из ультрадисперсных частии (УДЧ) титана; 2 - грануль состава УДЧ титана и 20 масс. \% УДЧ нитрида титана. Определен фазовый

(C) Siberian Federal University. All rights reserved

This work is licensed under a Creative Commons Attribution-NonCommercial 4.0 International License (CC BY-NC 4.0).

* Corresponding author E-mail address: chae@itam.nsc.ru

$$
-203-
$$


и гранулометрический состав, изучена внутренняя структура обработанных порошковых частиц.

Ключевые слова: сферические порошки, плазмотрон, плазменная струя, титан, нитрид титана, гранулирование.

\section{Введение}

Аддитивные технологии предоставляют инженерам новый подход для проектирования и производства деталей сложной формы. Они существенно уменьшают количество последующей обработки и улучшают качество продукции, производя детали, наиболее близкие к данным компьютерной модели [1]. Самые популярные аддитивные технологии, такие как селективное лазерное или электронно-лучевое плавление и лазерная наплавка, используют исходный материал в порошкообразной форме. Одно из основных требований к применению металлического порошка для получения надежных и повторяемых результатов - сферическая форма частиц [2]. Наиболее существенным преимуществом получения сферических порошков с использованием плазменного оборудования является производство порошков высокой чистоты химически активных металлов и сплавов с высокой температурой плавления, таких как титан, цирконий, тантал и т.п.; производство порошков с узким распределением частиц декамикронного размера. В качестве исходного сырья для получения сферических порошковых частиц, как правило, используют металлический порошок неравноосной формы [3, 4]. Необходимо отметить, что продукция крупных производителей металлических порошков, например «Полема» г. Тула, содержит частицы в широком диапазоне размеров для отдельной марки порошка, от ультрадисперсных частиц до частиц с декамикронным размером. Обработка в термической плазме исходного сырья без дополнительной классификации вызывает дефекты обработанных порошков [3]. Обработанные частицы на своей поверхности содержат сателлиты, образованные «налипанием» мелких частиц, что приводит к ограничению их использования в аддитивных технологиях. В работе [4] опубликованы экспериментальные результаты нового способа получения исходных материалов для аддитивных технологий, основанного на совмещенной технологии механического легирования и плазменной обработки, который позволил расширить спектр порошков по химическому составу, а соответственно, и область их применения.

Учитывая вышеописанные требования к применению порошковых частиц аддитивными технологиями и особенности методов их получения, в настоящей работе приведены экспериментальные исследования по получению сферических частиц на основе титана из гранулированного порошка, состоящих из множества ультрадисперсных частиц (УДЧ) исходного порошка, полученного механическим методом, с последующей сфероидизацией в плазменной струе.

Научный интерес также представляет получение плакированных частиц, состоящих из наночастиц тугоплавкого материала и металла-связки, с использованием технологии гранулирования с последующей обработкой в плазменной струе.

Введение модифицирующих порошков в расплав металла при сварке или литье в пропорциях до $0.1 \%$ от массы исходного металла влияет на повышение свойств конечного продукта. В процессе непрерывного охлаждения они являются дополнительными центрами кристаллизации, способствуя формированию мелкодисперсной глобулярной структуры сплава. Исходные 
ультра- и нанодисперсные частицы тугоплавкого материала имеют низкую смачиваемость расплавом, вследствие чего не могут активно воздействовать на кристаллическую структуру материала $[5,6]$. При вводе в расплав металла плакированных частиц увеличится смачиваемость, тем самым повысится эффективность центров кристаллизации.

Цель работы - исследование физико-химических характеристик порошков, полученных в плазменной струе при обработке гранул двух составов: 1 - гранулы, состоящие из УДЧ титана; 2 - гранулы состава УДЧ титана и 20 масс. \% УДЧ нитрида титана.

Поставленная цель достигалась решением следующих задач:

1) сфероидизировать порошковые гранулы, состоящие из металлических УдЧ фракций 40-80 и 80-125 мкм, в плазменной струе;

2) получить модифицирующие порошки микронного и субмикронного размеров состава $\mathrm{Ti}-20 \% \mathrm{TiN}$

3) исследовать фазовый состав, гранулометрический состав, морфологию поверхности, внутреннюю структуру полученных частиц.

\section{Методика эксперимента}

В работе использовали порошок титана марки ПТОМ-2. Определение гистограмм объемного и счетного распределений частиц проводилось на анализаторе размеров частиц $(0,04-$ 2000 мкм) LS 13320 (Beckman Coulter). Морфологию и элементный анализ получали с помощью электронного микроскопа Evo MA15 (Carl Zeiss). Классификацию порошковых частиц по размерам производили на вибростенде с использованием набора аналитических сит. Рентгенофазовый анализ обработанных (синтезированных) порошков проводили на дифрактометре ДРОН-4.0 с использованием монохроматизированного $\mathrm{Cu}_{\mathrm{Ka}}$-излучения.

\section{Результаты и обсуждение}

Получение сферических частиц порочка титана из гранулированных частиц,

Получение агломерированных частиц для плазменной обработки включало следующие этапы: (1) - выделение частиц фракции менее 20 мкм; (2) - подготовка порошкового сырья для получения гранул методом экструзии; (3) - классификация порошковых гранул по размерам (фракциям).

В качестве исходного порошка использовали выделенную фракцию с размерами частиц $\leq 20$ мкм. Средний размер частиц согласно гистограмме объемного распределения частиц по размерам составляет 18 мкм. Счетные гистограммы распределения частиц по размерам показывают наличие частиц в порошке с размерами менее 1 мкм, что подтверждают СЭМфотографии общего вида порошков (рис. 1). Отдельные частицы порошка титана имеют гантелеобразную форму.

\section{Подготовка гранул, состоящих из УДЧ титана}

В порошковые частицы добавляли 30 \% объемных долей клеевого связующего (полиэтиленгликоль) и механически перемешивали до образования однородной массы, после чего полученную смесь продавливали через сетку из нержавеющей стали с размером ячейки 200 мкм. Полученные гранулы сушили в вакуумном шкафу при температуре $120{ }^{\circ} \mathrm{C}$ в течение 8 ч.

$$
-205-
$$



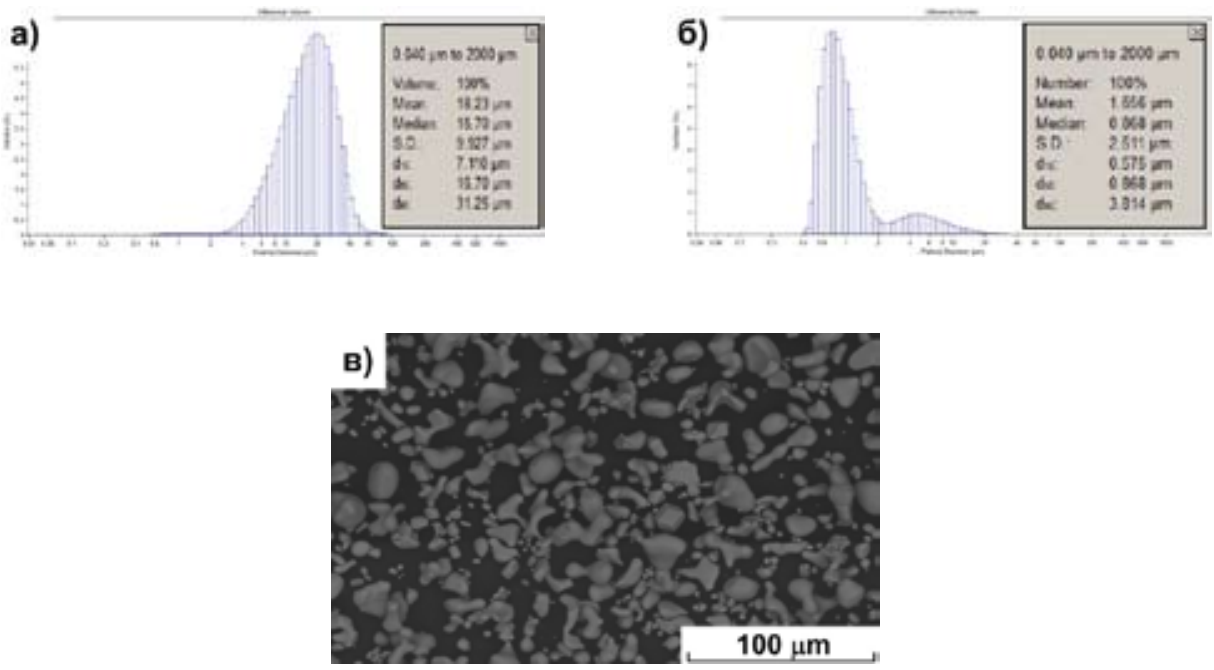

Рис. 1. Характеристики порошковых частиц титана: а - гистограмма объемного распределения частиц по размерам; б - гистограмма счетного распределения частиц по размерам; в - СЭМ-фотография общего вида порошковых частиц

Fig. 1. Characteristics of titanium powder particles: a - the histogram of the volumetric particle size distribution; $\sigma$ - the histogram of a counting particle size distribution; в - SEM photograph of the general view of the powder particles
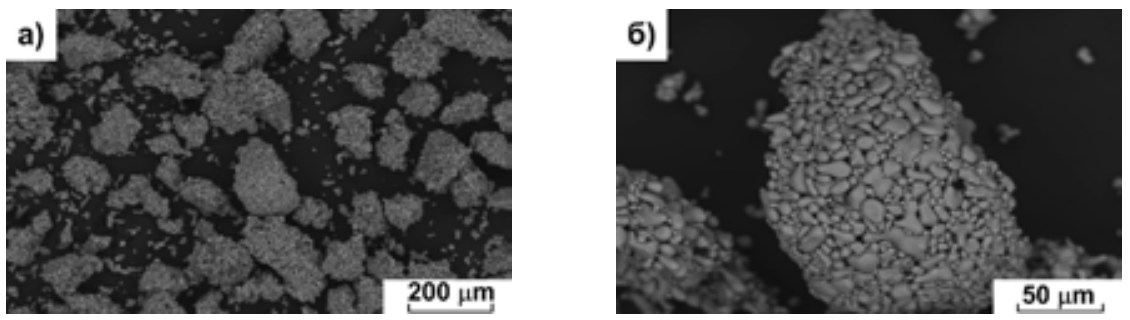

Рис. 2. Микрофотографии гранулированного порошка титана фракции 80-125 мкм (а) и отдельной частицы (b)

Fig. 2. General view of the granulated titanium powder of fraction of 80-125 microns (a); single particle (б)

Высушенные гранулы рассеивали на вибростенде с использованием набора аналитических сит, с выделением фракций +40-80 и +80-125 мкм. Необходимо отметить, что гранулированный порошок (рис. $2 a$ ) после рассева имеет значительное количество более мелких частиц. Агломерированные частицы (рис. 26) имеют округлую форму, сформированы из УдЧ исходного порошка. Следует отметить высокую пористость агломератов, которая обусловлена не только неплотной упаковкой УдЧ, но и появлением дополнительных газовых включений в процессе сушки компакта.

Сфероидизацию порошка проводили с помощью плазмотрона (2) с межэлектродной вставкой (МЭВ) мощностью до 50 кВт, установленного на водоохлаждаемом реакторе (4) с контролируемой атмосферой (рис. 3). Использовалась односторонняя инжекция обрабатываемого порошка непосредственно перед выходным сечением сопла плазмотрона. Основным плазмо-

$$
-206-
$$


образующим газом являлась смесь аргона и гелия. В качестве транспортирующего газа для ввода порошка в плазменную струю из дозатора (3) использовался аргон.

Обработка порошка проводилась при следующих значениях режимных параметров: расход основных рабочих газов $\mathrm{G}_{\mathrm{Ar}}=0,4$ г/c, $\mathrm{G}_{\mathrm{He}}=0,2$ г/c, расход вспомогательного газа (аргон), подаваемого на защиту анода, $\mathrm{G}_{\mathrm{Ar}}=0,14$ г $/ \mathrm{c}$, расход транспортирующего газа (аргон) $\mathrm{G}_{\text {carrier }}=0.05$ г $/ \mathrm{c}$, расход порошка $G_{\text {powder }}=1,5$ кг/ч, эффективная мощность плазмотрона составляла 14,8 кВт. Число Рейнольдса для указанных параметров было $\operatorname{Re} 150$, которое соответствует режиму квазиламинарной плазменной струи.

В результате обработки гранулированного порошка титана в плазменной струе получены сферические частицы, морфология которых представлена на рис. 4. Поверхность частиц чистая, на ней отсутствуют сателлиты, образующиеся в процессе испарения наиболее мелких частиц, с последующей конденсацией паров в виде мелкодисперсных и субмикронных частиц. На поверхности и по объему частицы видна структура, вызванная процессами кри-

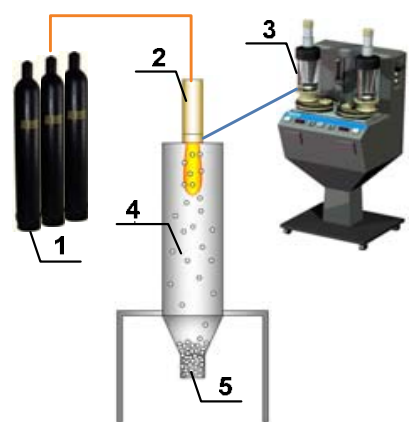

Рис. 3. Принципиальная схема экспериментальной установки: 1 - баллоны с плазмообразующим газом; 2 - плазмотрон с МЭВ; 3 - порошковый дозатор; 4 - водоохлаждаемый реактор; 5 - коллектор порошка

Fig. 3. Schematic diagram of the experimental setup: 1 - plasma forming gas cylinders; 2 - plasma torch with interelectrode insert; 3 - powder feeder; 4 -water-cooled chamber; 5 - powder collector
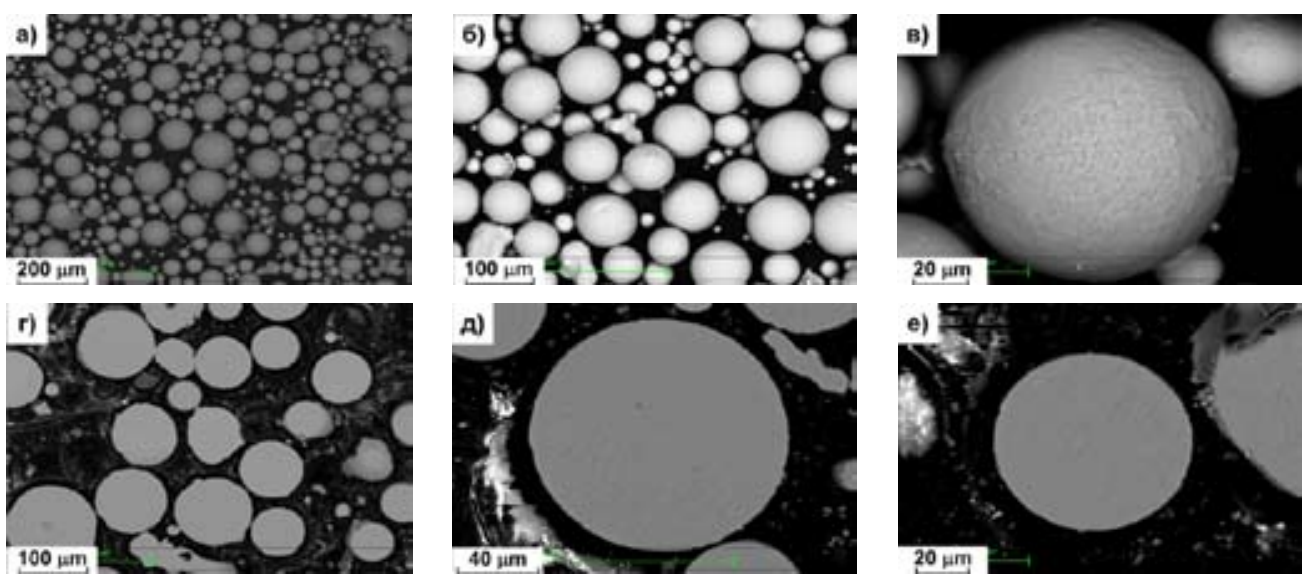

Рис. 4. СЭМ микрофотографии общего вида $(a, \sigma, 6)$ и шлифов частиц $(2, \partial, e)$ при разном увеличении

Fig. 4. SEM micrographs of general view $(a, \sigma, b)$ and cross sections of the particles $(2, \partial, e)$ at different magnifications 
сталлизации во время охлаждения частицы. Частицы имеют плотную однородную структуpy.

Гистограммы распределения обработанных порошковых частиц титана по размерам, фракции 40-80 и 80-125 мкм представлены на рис. 5. Гистограммы объемного распределения частиц по размерам показывают средний размер частиц 35 мкм. Сфероидизация в плазменной струе приводит к уплотнению частиц и частичному испарению материала с поверхности, что объясняет уменьшение размеров по сравнению с исходным порошком.

Рентгенофазовый анализ (рис. 6) полученного порошкового продукта показал наличие пиков, соответствующих только титану (номер карточки 44-1294).

Таким образом, получение металлических сферических порошков возможно при обработке в плазменной струе гранулированных частиц, состоящих из УдЧ исходного материала. В отличие от сфероидизации механически легированных агломератов [4], имеющих низкую
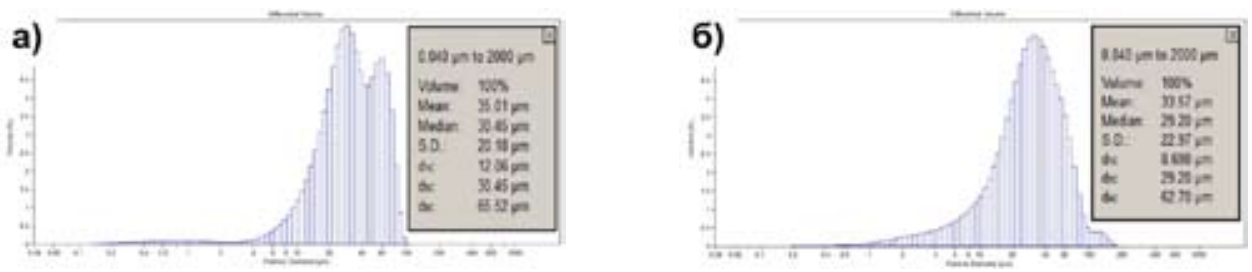

Рис. 5. Гистограмма объемного распределения по размерам порошковых частиц титана, полученных в плазменной струе из агломерированных частиц 40-80 мкм (а) и 80-125 мкм (б)

Fig. 5. The histogram of the volumetric particle size distribution of titanium, obtained from plasma jet treatment from agglomerated particles of a) 40-80 microns and б) 80-125 microns

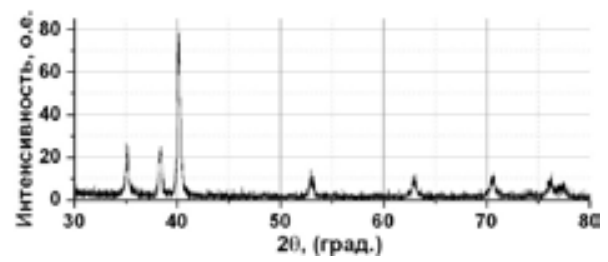

Рис. 6. Рентгенограмма обработанных частиц титана

Fig. 6. X-ray scattering diagram of the treated titanium particles
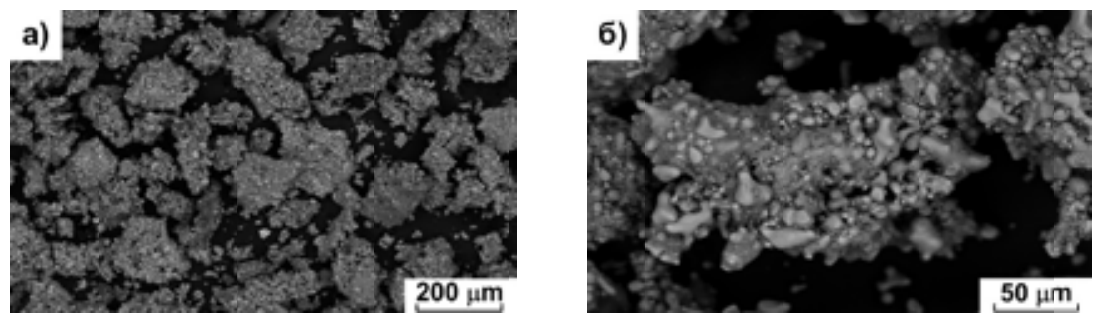

Рис. 7. Микрофотографии агломерированного порошка титана фракции 80-125 мкм (а) и отдельной частицы (б)

Fig. 7. Micrographs of agglomerated titanium powder of fraction of 80-125 microns (a) and single particle (б) 

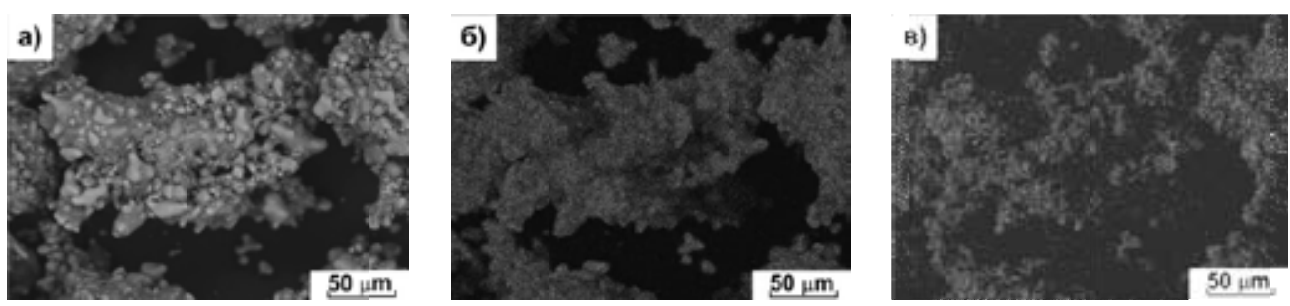

Рис. 8. Элементный анализ гранулированной частицы, полученный с помощью сканирующей электронной микроскопии: а - анализируемая частица, б - распределение фазы титана; в - распределение фазы азота на поверхности частицы

Fig. 8. Element analysis of a granulated particle, obtained by scanning electron microscopy: a - the particle being analyzed, $\sigma$ - the distribution of the titanium phase and в - the distribution of the nitrogen on the surface of the particle

механическую прочность, которая приводит к их разрушению и, как следствие, образованию множества сателлитов на поверхности частиц во время термической обработки, удаление которых с поверхности требует дополнительной операции путем промывки в ультразвуковой ванне, сфероидизация порошка, выполненного с использованием технологии гранулирования, позволяет получать частицы с чистой поверхностью.

\section{Получение сферических модифицированных частии на основе титана}

Получение гранулированных частиц состава $\mathrm{Ti}-20$ масс. \% TiN для плазменной обработки включает описанные ранее технологические этапы. Механическое перемешивание порошковой смеси осуществляли в течение 8 ч с использованием вибростенда.

Полученные гранулированные частицы фракции 80-125 $\mu \mathrm{m}$, сформированные из УДЧ исходной порошковой композиции, имеют неправильную форму, морфология которых представлена на рис. 7. Методом элементного анализа были получены карты распределения элементов по поверхности гранулированной частицы. Результатом механического перемешивания порошковых компонент является равномерное их распределение в смеси (рис. 8).

В результате плазменной обработки при тех же режимных параметрах получены сферические частицы, морфология которых представлена на рис. 9. Следует отметить наличие как плотных частиц, так и частиц с содержанием внутренних пор. Процесс обработки гранулированных частиц включает следующие этапы: (1) нагревание гранул до момента, когда их поверхность начинает плавиться; одновременно, в результате теплового расширения, газ выходит из пористого объема частицы, чтобы высвободиться в окружающее пространство; (2) осуществляется плавление и коалесценция компонентов УдЧ, а также их вовлечение в растущий слой расплава благодаря смачиванию; (3) завершение плавления гранулы и образование плотной сферической частицы либо частицы с распределенными газовыми объемами [7].

Необходимо отметить равномерное распределение элементов, соответствующих фазам титана и азота, как по поверхности частицы, так и по их объему (рис. 9 и 10). Поверхность полученных частиц не идеально ровная, на поверхности присутствуют каверны (рис. 11). Образование дефектной структуры связано с процессом кристаллизации, эффективными центрами которой являются тугоплавкие наночастицы нитрида титана. При этом шлиф частиц (рис. 12)

$$
-209-
$$



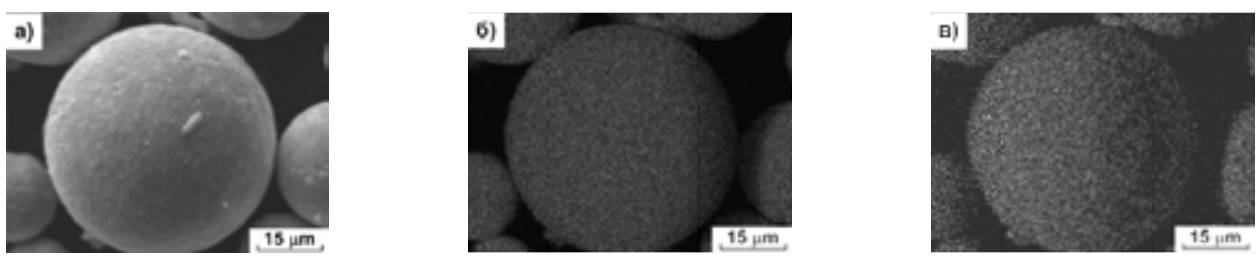

Рис. 9. Элементный анализ обработанной частицы, полученный с помощью сканирующей электронной микроскопии: а - анализируемая частица, б - распределение фазы титана; в - фазы азота по поверхности частицы

Fig. 9. Element analysis of the treated particle obtained by scanning electron microscopy: $\mathrm{a}-$ the particle being analyzed; $\sigma$ - the distribution of the titanium phase and $\mathrm{B}-$ the distribution of the nitrogen on the surface of the particle
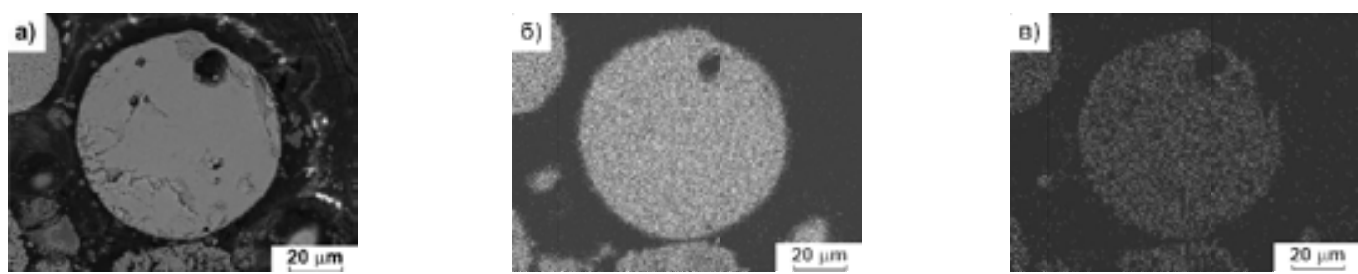

Рис. 10. Элементный анализ частицы, полученный с помощью сканирующей электронной микроскопии: a - шлиф частицы; б - распределение фазы титана; в - фазы азота по объему частицы

Fig. 10. Element analysis of a particle obtained by scanning electron microscopy: a - cross section of particle; $\sigma$ - volumetric distribution of the titanium and в - volumetric distribution of the nitrogen
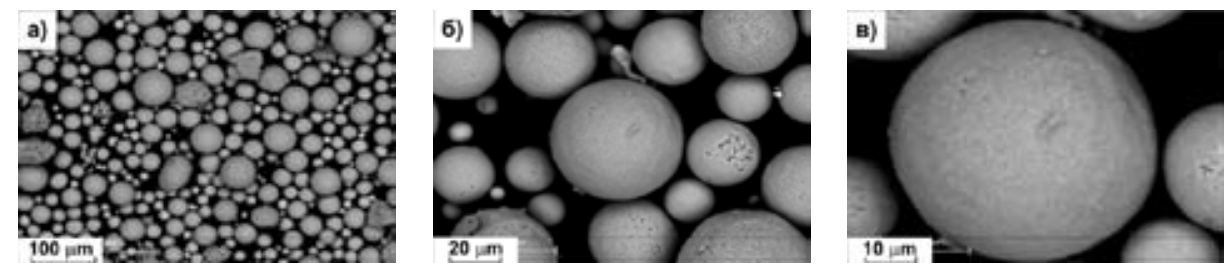

Рис. 11. Микрофотографии порошковых модифицированных частиц титана, полученных из гранулированных частиц размером 80-125 мкм при разном увеличении

Fig. 11. Micrographs of modified titanium particles obtained from granulated particles with a size of 80-125 microns with different magnifications
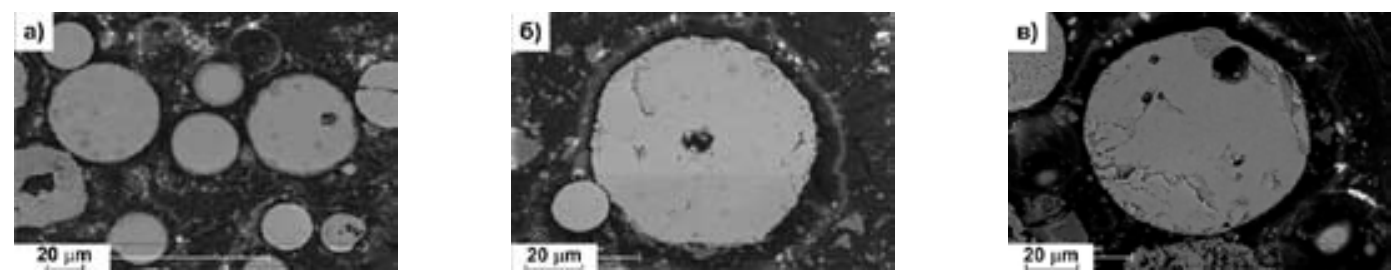

Рис. 12. Микрофотографии шлифа обработанных частиц титана

Fig. 12. Micrographs of cross section of the treated titanium particles 
отображает структуру неоднородного материала, в котором распределены поровые пространства.

Гистограммы распределения по размерам модифицированных частиц титана, полученных в плазменной струе из гранулированных частиц размером 80-125 мкм, представлены на рис. 13.

Результаты рентгенофазового анализа (рис. 14) обработанных частиц показали наличие пиков, соответствующих только титану (номер карточки 44-1294) и нитриду титана (номер карточки 38-1420).
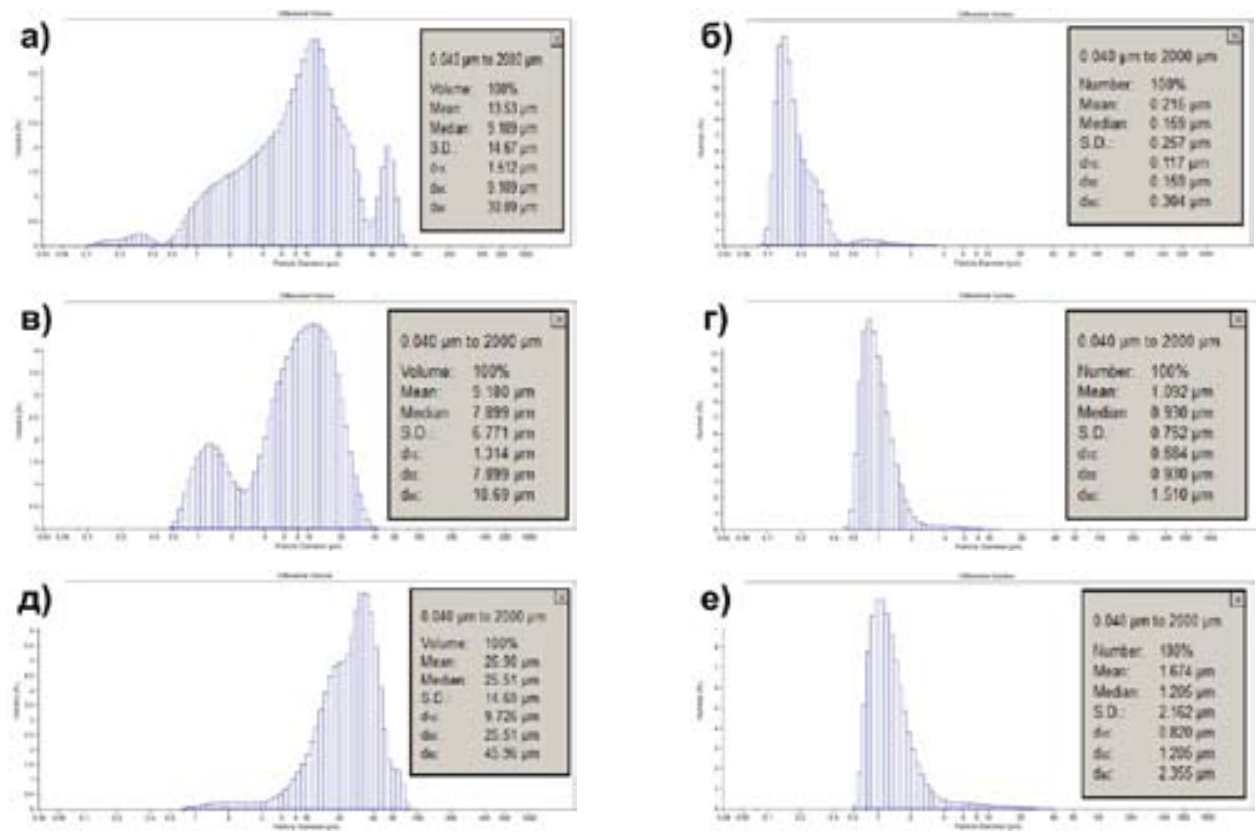

Рис. 13. Гистограмма распределения модифицирующих частиц титана по размерам: а и б-характеристики частиц с верхнего фланца реактора; в и г - характеристики частиц, осевших на стенки реактора; д и е характеристики частиц из порошкового приемника: а), в) и д) гистограмма объемного распределения частиц по размерам; б), г), е) гистограмма счетного распределения частиц по размерам

Fig. 13. Histogram of the size distribution of titanium modifying particles: a and $\sigma-$ particle characteristics from the upper flange of the reactor, в and $г$ - characteristics of particles deposited on the walls of the reactor, д and e-characteristics of particles from the powder collector: a), б) and д) a histogram of the volumetric distribution of particle size; б), г), e) a histogram of a counting particle size distribution

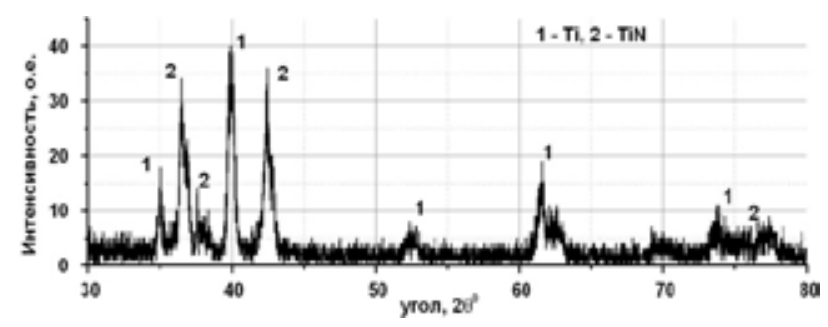

Рис. 14. Рентгенограмма обработанных агломерированных частиц титана

Fig. 14. X-ray scattering diagram of the treated agglomerated titanium particles 
Получен композиционный порошок, состоящий из сферических частиц дисперсностью от 0.1 до 80 мкм, в которых тугоплавкие ультра- и наночастицы нитрида титана равномерно распределены по всему объему металла-связки (титан) и полностью им плакированы. Показано, что независимо от размера частицы наследуют форму, структуру и равномерное распределение элементов по поверхности и объему материала.

\section{Заключение}

Используя комбинированный метод получения сферических частиц, включающий порошковое гранулирование и плазменную обработку, получили химически чистый сферический порошок титана при обработке механически подготовленных гранул, состоящих из УдЧ исходного материала. Частицы имеют ровную поверхность, на которой отсутствуют сателлиты. Внутренняя структура материала сплошная.

По отработанной комбинированной технологии был получен порошок-модификатор состава Ti+20 масс. \% TiN. Обработанные частицы имеют сферическую форму, на своей поверхности могут содержать дефекты в виде каверн, микронного размера в диаметре. Также отмечено отсутствие сателлитов на поверхности частиц. Измерен гранулометрический состав проб, взятых с верхнего фланца, боковых стенок и приемника порошка реактора. Показано, что независимо от размера частицы наследуют форму, структуру и равномерное распределение элементов по поверхности и объему материала.

Технология гранулирования позволяет повысить эффективность использования исходного порошкового материала, применяемого для получения сферических порошков. Сфероидизированные частицы имеют плотную однородную структуру с чистой поверхностью. Подобная технология с последующей обработкой в плазме позволяет также создавать модифицирующие порошки для различных применений.

Работа выполнена в рамках Программы фундаментальных научных исследований государственных академий наук на 2013-2020 годы (проект ААAA-A17-117030610124-0).

\section{Список литературы}

[1]. Weller C., Kleer R., Piller F.T. Economic implications of 3D printing: Market structure models in light of additive manufacturing revisited, International Journal of Production Economics, 2015, $164,43-56$

[2] Herzog D., Seyda V., Wycisk E., Emmelmann C. Additive manufacturing of metals, Acta Materialia, 2016, 117 371-392

[3] Kotlyarov V.I., Beshkarev V.T., V.E. Kartsev, V.V. Ivanov, A.A. Gasanov, E.A. Yuzhakova, A.V. Samokhin, A.A. Fadeev, N.V. Alekseev, M.A. Sinayskiy, E.V. Tretyakov. Production of spherical powders on the basis of group IV metals for additive manufacturing, Inorganic Materials: Applied Research, 2017, 8(3), 452-458

[4] Григорьев А.В., Разумов Н.Г., Попович А.А., Самохин А.В. Плазменная сфероидизация порошков на основе сплавов $\mathrm{Nb}-\mathrm{Si}$, полученных механическим легированием. Металлургия и материаловедение. Научно-технические ведомости Санкт-Петербургского государственного политехнического университета, 2017, 23(1), 247-255 [Grigor’ev A.V., Razumov N.G., Popovich 
A.A., Samohin A.V. Plasma spheroidization of powders based on Nb-Si alloys obtained by mechanical doping, Metallurgy and Materials Science Scientific and technical lists of the St. Petersburg State Polytechnic University, 2017, 23(1), 247-255 (in Russian)].

[5] Оришич А.М., Черепанов А.Н., Шапеев В.П., Пугачева Н.Б. Наномодифицирование сварных соединений при лазерной сварке металлов и сплавов. Новосибирск: СО РАН, 2014. 252 c. [Orishich A.M., Cherepanov A.N., Shapeev V.P., Pugachev N.B. Nanomodification of welded joints in laser welding of metals and alloys, Novosibirsk, SB RAS, 2014. 252 p. (in Russian)]

[6] Крушенко Г.Г., Ямских И.С., Бонченков А.А., Мишин А.С. Повышение качества чугунных отливок с помощью нанопорошков. Металлургия машиностроения, 2002, 2(9), 20-21 [Krushenko G.G., Yamskih I.S., Bonchenkov A.A., Mishin A.C. Improving the quality of cast iron castings using nanopowders. Metallurgy of machine building, 2002, 2(9), 20-21 (in Russian)]

[7] Solonenko O.P. Criterion conditions for the formation of hollow microspheres from plasmatreated agglomerated particles, Thermophysics and Aeromechanics, 2014, 21(6), 735-746 